Article

\title{
Gender Differences in the Relationship between Work-Life Balance, Career Opportunities and General Health Perception
}

\author{
Francesco Pace $^{1, * \mathbb{D}}$ and Giulia Sciotto ${ }^{2} \mathbb{B}$
}

Citation: Pace, F.; Sciotto, G. Gender Differences in the Relationship between Work-Life Balance, Career Opportunities and General Health Perception. Sustainability 2022, 14 , 357. https://doi.org/10.3390/ su14010357

Academic Editors: Hyo Sun Jung, Silvia Platania and Anna Paolillo

Received: 2 December 2021

Accepted: 28 December 2021

Published: 29 December 2021

Publisher's Note: MDPI stays neutral with regard to jurisdictional claims in published maps and institutional affiliations.

Copyright: (C) 2021 by the authors. Licensee MDPI, Basel, Switzerland. This article is an open access article distributed under the terms and conditions of the Creative Commons Attribution (CC BY) license (https:// creativecommons.org/licenses/by/ $4.0 /)$.
1 Department of Economics, Business and Statistics, University of Palermo, Viale delle Scienze ed.13, 90128 Palermo, Italy

2 Department of Psychology, Educational Sciences and Human Movement, University of Palermo, Viale delle Scienze ed.15, 90128 Palermo, Italy; giulia.sciotto@unipa.it

* Correspondence: francesco.pace@unipa.it

\begin{abstract}
Although gender equality is increasingly promoted both in the workplace and in society, and women have now fully entered the workforce, the issue of gender differences in relation to career advancement still seems open. Although gender roles no longer clearly define who is responsible for home care and who is responsible for job duties, some research shows that the conflict between family and work life appears to be a greater problem for women than for men. The aim of this study was to examine the relationship between career opportunities, work-life balance, and well-being perception separately in both female $(n=499)$ and male $(n=557)$ respondents in order to shed light on the role of gender. A multi-group analysis showed that the structural paths of the models differ by gender. For women, the relationships between career opportunities and work-life balance and between career opportunities and the perception of general health have significantly lower values compared to results from the group of men, while the perception of work-life balance affects well-being more significantly when compared to the male counterpart. Implications on the importance of the connection between career and the valorization of personal life duties are further discussed.
\end{abstract}

Keywords: work-life balance; career opportunities; well-being; gender

\section{Introduction}

Over the past few decades, massive changes in society and in the workplace have occurred. For example, the participation of women in the workforce-while fulfilling family responsibilities - and the growing heterogeneity of the workforce in general are now a fact, as is the rise in teleworking or the habit of bringing work home. These changes have brought attention to the need to address diversity management, as well as to the boundaries between employee work and personal life. The study of gender differences, for example, is closely connected to the study of work-life balance, given the different gender-based social roles that women and men stereotypically play according to collective ideals. Therefore, the study of gender-related work-life balance has become extremely salient for the well-being of individuals and for the overall good functioning of organizations.

Work-life balance occurs when the time spent on the job role does not limit the time dedicated to personal life (for example, engaging in leisure or family activities). It is an important antecedent of job and life satisfaction and a critical job resource that makes work demands be experienced more positively, for example, by creating a work-family climate where workers feel they do not have to sacrifice effectiveness in their family role to perform their jobs [1]. In fact, work-family balance is presumably composed of three elements: (a) time balance, consisting in dedicating an equal amount of time to both work and family roles; (b) involvement balance, consisting in dedicating an equal amount of psychological involvement in the said roles; (c) satisfaction balance, consisting in being equally satisfied in both work and family roles [2]. The emphasis on equity included multiple times in this definition, however, has been questioned. Work-life balance may largely depend on 
how this balance is perceived. For example, it is possible to work long hours and still not perceive any negative consequences from the inequality between working hours and time left for non-working activities [3]. Either way, the satisfaction with the balance between work and personal life can be influenced not only by individual perceptions, but also by other job characteristics such as organizational culture, significance of the work, and the presence of work-life initiatives [4].

Recently, work-life balance has been profusely linked to job and life satisfaction [3,5-7] and the well-being of individuals and families [8,9], and it has been negatively associated with psychological strain [3] and work-related stress [7,10]. In fact, having to balance multiple roles (worker, parent, husband or wife, brother or sister, and so on) forces them to compete for the same resources (for example, time and energy), which can lead to strain, stress symptoms, or health problems [11].

\subsection{The Gender Factor in Work-Life Balance}

The effect of gender on a variable that simultaneously includes the work component and the family life component is particularly interesting.

Traditionally, men and women have occupied different social roles, in terms of the amount of time spent on work and family duties; stereotypically, men work full-time outside their homes, while women take care of domestic and family duties. Gender-based role divisions are actually part of the collective culture [12]. Females are associated with caring, listening, and kindness skills, while males are associated with authority, aggression, domination, and autonomy [13]. Consequently, although these clearly differentiated roles are now anachronistic, the likelihood that family responsibilities still pertain to the charge of women remains high [14]. Studies have found that women tend to spend more hours on family activities than men, but that the hours spent on work activities were the same for men and women $[9,15]$. This may explain why in work-life balance studies, the gender variable has mainly been examined from the female perspective [16-18]. In fact, despite the enactment of several pieces of legislation on equal opportunities, work-life balance may still be far from being gender-neutral, according to a study that examined seven countries (the UK, Norway, the Netherlands, India, Japan, and South Africa) [19]. Women continue to retain "a much closer tie with family care and domestic responsibilities linked to current manifestations of the gender order" [19] (p. 364), that is, the socially and historically established hierarchical difference between men and women.

However, the traditional male role has changed [20]. The issue of work-life balance for men is made complex by the load of social expectations regarding their career, on the one hand, and by expectations about their role within the family, on the other. Men are expected to be the main financial providers in the family, and this may result in them having to work longer hours. Moreover, since men also desire to spend time at home with their families, they may end up facing higher levels of stress and role overload [20]. The achievement of higher levels of work-life balance, however, has been associated with a better quality of life among all those men who, as a result of this balance, have been able to achieve greater involvement and investment in their family role [2].

The evidence for gender differences in work-life balance is mixed. According to some studies that have examined both Western and Eastern cultures (Australia, New Zealand, the USA, and East Europe), there is no evidence of real or significant gender differences [21-25]. According to these studies, the experience of work-life balance is related to job and life satisfaction equally in both men and women. On the contrary, according to other cross-cultural studies, the effect of gender remains significant, with men reporting higher levels of work-life balance than women [26], and women experiencing higher levels of conflict between work and family life [10,27-29]. Women report significant difficulties in balancing their work and family life due to the lack of sufficient time, support from their husbands, and cultural norms and gender biases in the workplace [30]. Work-life balance issues can also affect women's health, causing stress, depression, headache, muscle tension, 
and weight gain [17], and can become a barrier to their career advancement compared to their male counterparts.

\subsection{Work-Life Balance and Career Opportunities}

Considering what has been said so far about the implications of gender differences on work and family life, it is reasonable to assume that inequalities between men and women also exist in career opportunities. The literature on gender-related career opportunities is highly unbalanced on the side of women, as it is probably rare to find traces of structured and persistent stereotypical discrimination against men in the workplace.

Research indicates that gender is still a common barrier to career development in many contexts. Women are under-represented in many sectors and roles [31,32] and are less likely to be employed full-time [33].

Work-life conflict is often cited as a contributing factor to these issues since household and childcare responsibilities might severely and negatively influence women's career advancements [34].

Women are less satisfied with their career opportunities [32], with their job, and their work-life balance in general compared to their male colleagues, who report higher job and life satisfaction levels and lower work-related stress levels [35].

It cannot be taken for granted that career opportunities lead to well-being. Usually, women have to work harder than men if they want to reach higher positions (the so-called "glass ceiling" [36] and "gender segregation" [37]). In turn, working harder would lead to an increased conflict between work and life [38], and in fact, accepting a higher position very often leads to a lower work-life balance. A positive relationship between perceived work-life balance and career advancement motivation was found [39].

It would seem that work-life balance and career opportunities are inextricably linked, at least as far as female workers are concerned. Therefore, it is presumable that organizational policies aimed at acknowledging and supporting the multiple and parallel demands of family and work, and aimed at making their employees achieve a good level of work-life balance, should also favor the career advancements of women.

We argue that career opportunities alone, if not supported by work-life balance practices and policies, may not be sufficient to generate well-being. Studies have shown that practices such as telecommuting, childcare services, flexible hours, and so on, increase employee satisfaction and motivation [40] and reduce absenteeism and turnover [41] and work-related stress [42]. Moreover, since the presence of female employees in the organization seems to encourage the implementation of measures that promote work-life balance [43], the choice to invest in work-life balance policies could be functional and sustainable, as male employees would certainly benefit as well.

The aim of the study was therefore to verify if:

Hypothesis 1. (H1). Perceived career opportunities relate to employees' well-being directly and indirectly through perceived work-life balance.

Hypothesis 2. (H2). The relationships between the study variables differ between males and females.

\section{Materials and Methods}

\subsection{Sample}

The research population for this study is a convenience sample of 1056 Italian workers, contacted through emails or direct contact and invited to fill in an online form or a printed version of the questionnaire. Overall, $53 \%$ of the subjects are male and $47 \%$ are female; mean age is 46.8 years old for males $(\mathrm{SD}=10.6)$ and 43.9 years old for females $(\mathrm{SD}=11.1)$, from a range between 20 and 67 years old. Regarding marital status, $61 \%$ of males are married, $17 \%$ are single, $6 \%$ are separated or divorced, another $6 \%$ live together with their partner, $1 \%$ are widowers, and finally, $9 \%$ did not declare their marital status. As for the female sample, $49 \%$ are married, $25 \%$ are single, $9 \%$ live together with their partner, $7 \%$ 
are separated or divorced, 3\% are widows, and finally, 7\% did not declare their marital status. A total of $31 \%$ of the male sample is made up of workers who perform back-office functions (little contact with the public), 43\% are workers who mainly perform front-office functions (frequent interactions with the public), 24\% perform both functions, and $2 \%$ did not fill in the item. As for the female sample, it is made up of $16 \%$ of workers who perform back-office functions, $56 \%$ of workers who mainly perform front-office functions, $26 \%$ who perform both functions, and $2 \%$ who did not fill in the item. In the male sample, $28 \%$ work in the administrative sector, $23 \%$ in the service sector, another $23 \%$ are in the armed forces, $14 \%$ work as teachers, and $12 \%$ work in the health sector. In the female sample, $20 \%$ work in the administrative sector, $33 \%$ in the service sector, $25 \%$ in the health sector, $18 \%$ work as teachers, and $4 \%$ are in the armed forces.

\subsection{Measures}

Career opportunities perception was measured using the 3 items of the Career Possibilities scale from the Italian version of the Questionnaire on the Experience and Evaluation of Work (QEEW) [44,45]. It assesses the perception of the possibilities offered by the organization to improve employees' career status. An example of an item is: "Does your job give you the opportunity to be promoted?". The items were assessed using a 4-point Likert scale from (1) "never/absolutely no" to (4) "always/absolutely yes"; a higher score indicates the higher presence of the construct. Cronbach's alpha for this study is 0.72 .

Work-life balance perception was measured using 3 items adapted from the metaanalysis work [1], which assess the perceived balance between one's work and personal life. Cronbach's alpha for this study is 0.72. An example of an item is: "My organization is adequately understanding about my requests related to my family obligations".

Health perception was measured using the 12-item version of the General Health Questionnaire (GHQ-12) [46]. This questionnaire has already been used successfully in several studies aimed at measuring work-related well-being [47]. The first 6 items have a positive value and investigate the perception of being able to concentrate, to cope with everyday problems, and to make decisions. The frequency is rated on a 4-point Likert scale (from 1 = "much less than usual" to $4=$ "much more than usual"). An example of an item is: "In recent times, I felt able to face problems". The remaining 6 items have a negative value and investigate the presence of worries, sleep problems, perceptions of distrust, tension, and unhappiness. The frequency is rated on a 4-point Likert scale (from $1=$ "No" to $4=$ "much more than usual"). An example of an item is: "In recent times, I felt constantly under strain". The scores of the last 6 items were reversed, so that overall high scores on the scale corresponded to high levels of perceived well-being. Cronbach's alpha for this study is 0.85 .

\subsection{Data Analysis}

Descriptive data analysis, Pearson correlations, and Cronbach's alpha coefficients were tested through SPSS 27 (IBM, Armonk, NY, USA). A confirmatory factor analysis (CFA) and a multi-group analysis were carried out with Mplus 8 (Muthén and Muthén, Los Angeles, CA, USA). Measurement invariance was tested by comparing the two samples based on gender, and the indices of goodness of fit to the data were evaluated. Multiplegroup confirmatory factor analysis (MGCFA) was used to test and compare progressively more constrained models to assess the following measurement invariance: configural, metric, scalar, and strict. The additional constraints are appropriate and can be maintained if the model's chi-square does not change significantly, and if the decrease in Comparative Fit Index (CFI) between adjacent nested models is less than 0.01 . When there is support for measurement invariance, structural invariance can be examined. The bootstrapping method with 5000 replications was used to assess the significance of indirect effects. The method of estimation was maximum likelihood (ML). The following criteria were used to evaluate the goodness of fit: $\chi 2$ likelihood ratio statistic, Tucker-Lewis index (TLI), comparative fit index (CFI), and the root mean square error of approximation (RMSEA) 
with associated confidence intervals. Values of RMSEA smaller than 0.06 indicate a good fit, and CFI and TLI values greater than 0.90 indicate an acceptable fit [48].

\section{Results}

Means, standard deviations, and correlations between the study variables are shown in Table 1.

Table 1. Means, standard deviations, and correlations among study variables (male sample $n=557$; female sample $n=499$ ).

\begin{tabular}{cccccc}
\hline & \multicolumn{2}{c}{ Descriptive } & \multicolumn{3}{c}{ Correlations $^{\mathbf{1}}$} \\
\hline Variables & Mean & SD & $\mathbf{1}$ & $\mathbf{2}$ & $\mathbf{3}$ \\
\hline 1. Career opportunities & $2.30(2.12)$ & $1.04(0.98)$ & 1 & $0.249^{* *}$ & $0.290^{* *}$ \\
2. Work-life balance & $2.81(2.65)$ & $0.95(0.90)$ & 0.080 & 1 & $0.326^{* *}$ \\
3. General health perception & $2.37(2.39)$ & $0.75(0.77)$ & $0.171^{* *}$ & $0.311^{* *}$ & 1 \\
\hline
\end{tabular}

${ }^{1}$ Correlations below the diagonal are for the female sample, and correlations above the diagonal are for the male sample. Mean and SD for the female sample are in parentheses. ${ }^{*} p<0.05 ;{ }^{* *} p<0.01$.

From the analysis of the correlation matrices of the two samples, some notable differences have emerged. First, in the female sample, work-life balance does not correlate with career opportunities, while the correlation between the two variables is significant for males. Second, each correlation value is significantly lower for females. Table 2 shows the goodness-of-fit values of, respectively, the two CFA models separately for both samples, the multigroup analyses for measurement invariance, and the structural models.

Table 2. Goodness-of-fit values of CFA models and multigroup analysis for measurement invariance (ML estimation; male sample $n=557$; female sample $n=499$ ).

\begin{tabular}{cccccccc}
\hline \multirow{2}{*}{ Models } & \multicolumn{7}{c}{ Model Fit } \\
\cline { 2 - 8 } & $\chi^{\mathbf{2}}$ & df & CFI & TLI & RMSEA (90\% CI) & $\Delta$ M & $\Delta$ CFI \\
\hline Model for males & 17.500 & 8 & 0.982 & 0.967 & $0.048(0.016-0.079)$ & \\
Model for females & 19.282 & 8 & 0.973 & 0.950 & $0.054(0.023-0.086)$ & \\
M1: Configural & 36.781 & 16 & 0.978 & 0.959 & $0.051(0.029-0.073)$ & M1-M2 & 0.005 \\
M2: Metric & 45.613 & 20 & 0.973 & 0.960 & $0.051(0.031-0.071)$ & M2-M3 & 0.003 \\
M3: Scalar & 53.179 & 24 & 0.970 & 0.962 & $0.050(0.032-0.068)$ & M3-M4 & 0.008 \\
M4: Strict & 65.341 & 28 & 0.962 & 0.961 & $0.050(0.034-0.067)$ & \\
Structural model for males & 18.800 & 12 & 0.988 & 0.976 & $0.036(0.029-0.062)$ & \\
Structural model for females & 21.536 & 12 & 0.979 & 0.964 & $0.040(0.040-0.067)$ & & \\
Structural model across groups & 71.741 & 32 & 0.963 & 0.952 & $0.048(0.033-0.064)$ & &
\end{tabular}

Each model shows a good fit. The measurement invariance analyses provide overall good evidence of the non-existence of substantial item bias in the data, indicating that measures can be meaningfully compared across groups. In the first step of the multigroup analysis, the two structural equation models for both samples were examined separately. To exclude other intervenient variables, we controlled for age, marital status, and job sector. Both models yielded very good fit to the data: $\chi^{2}(\mathrm{df}=12)=18.8, p<0.01$; RMSEA $=0.04$ $(0.029-0.062) ; \mathrm{CFI}=0.99 ; \mathrm{TLI}=0.98 ; \mathrm{SRMR}=0.04$ for the male sample; $\chi^{2}(\mathrm{df}=12)=21.536$, $p<0.01$; RMSEA $=0.04(0.040-0.067) ; \mathrm{CFI}=0.98$; $\mathrm{TLI}=0.96$; $\mathrm{SRMR}=0.04$ for the female sample. Results from the subsequent comparison of the single analysis across both groups also show a good fit, thus supporting an invariant pattern of relationships among the study variables across the male and the female samples. Structural models are graphically represented in Figure 1. 


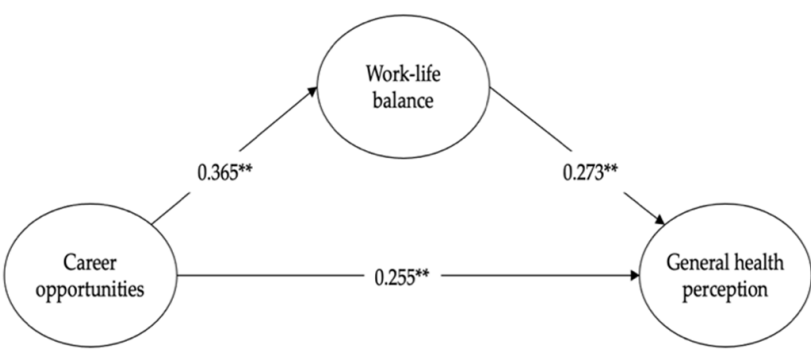

(a)

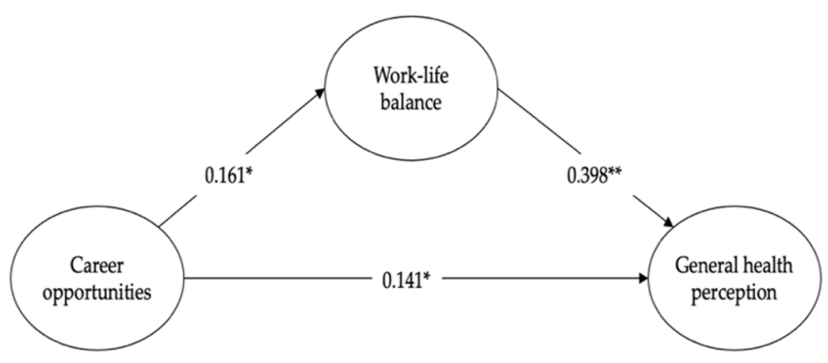

(b)

Figure 1. The two structural models: (a) the model for the male sample $(n=557)$; (b) the model for the female sample $(n=499)$. ${ }^{*} p<0.05 ;{ }^{* *} p<0.01$.

As anticipated by the patterns found in the correlation matrices, the two models differ significantly. For males, career opportunities are positively related to work-life balance $\left(\beta=0.365^{* *}\right.$, se $\left.=0.07\right)$ and general health perception $\left(\beta=0.255^{* *}\right.$, se $\left.=0.06\right)$; work-life balance also positively relates to general health perception $\left(\beta=0.273^{* *}\right.$, se $\left.=0.06\right)$. Career opportunities act on a positive general health perception directly and indirectly through a good perception of the work-life balance. For females, career opportunities are positively related to work-life balance $(\beta=0.161 *$, se $=0.08)$ and general health perception $(\beta=0.141 *$, se $=0.06)$; however, values are significantly lower compared to the male counterparts. On the other hand, work-life balance is positively related to general health perception $\left(\beta=0.398^{* *}\right.$, se $\left.=0.06\right)$ to a greater extent compared to the male sample. Career opportunities act on general health perception directly and indirectly through the effect of work-life balance. The latter shows a stronger relationship with general health than the career opportunities perception. We can conclude that both $\mathrm{H} 1$ and $\mathrm{H} 2$ are confirmed. Indirect effects values are shown in Table 3.

Table 3. Indirect effects using bootstrap with 5000 replications (ML estimation; male sample $n=557$; female sample $n=499$ ).

\begin{tabular}{lccc}
\hline Indirect Effects & Est. & S.E. & C.I. 95\% \\
\hline $\begin{array}{c}\text { Male sample } \\
\text { Career opp. } \rightarrow \begin{array}{c}\text { Work-life balance } \rightarrow \text { General health } \\
\text { Female sample }\end{array}\end{array}$ & $0.100 * *$ & 0.027 & $0.051,0.157$ \\
$\begin{array}{c}\text { Career opp. } \rightarrow \text { Work-life balance } \rightarrow \text { General health } \\
{ }^{*} p<0.05 ; * * p<0.01 .\end{array}$ & $0.064 *$ & 0.033 & $0.005,0.127$ \\
\hline
\end{tabular}

\section{Discussion}

Given the lack of research associating gender, career opportunities, work-life balance, and an outcome related to individual health all at the same time, the aim of this research was therefore to fill this void. To this end, a multigroup methodology was used so that the different structural paths of the model between men and women could emerge. The subjects' perceptions of the opportunities given by their organization to progress and improve their career, and their perception of the amount of time they are able to dedicate to other nonwork activities were tested. An outcome related to the perception of individual general health status was then identified (for example, the ability to concentrate and cope, or the presence of tiredness, sleep problems, states of tension, and so on). We hypothesized that the career opportunities would relate to general health perception both directly and indirectly through work-life balance, and that this relationship could differ by gender, controlling for other variables such as age, marital status, and job sector. Indeed, the mediation model showed different values between the two samples. In both, career opportunities were positively related to work-life balance, and both variables were positively related to the perception of general health. However, the female sample showed lower scores both in the perception of work-life balance and in the perception of career opportunities. Furthermore, the relationship between career opportunities and the perception of well- 
being was significantly weaker compared to the male sample. On the contrary, the link between work-life balance and the perception of well-being appears to be stronger among women than among men. We can deduce that both variables seem to be equally influential on men's perception of general health, but that among women, work-life balance seems to have a greater weight, also considering the perception of fewer career opportunities.

Differences in terms of perception of their own career opportunities would lead one to think that women are inclined to foresee fewer career opportunities for themselves than their male counterparts. Furthermore, the greater significance of work-life balance in generating well-being for women may justify the interest of researchers and organizations in studying what the ideal work-life balance consists of and what employers can do to ensure that women reach better levels of well-being. Additionally, the results show that achieving an adequate balance between private and working life can be closely linked to career opportunities. On the one hand, it could enable women to accept career advancements without these having an impact on their free time. On the other hand, women with better psychophysical conditions, as a consequence of a good work-life balance, may also be better and more empowered workers, who would therefore tend to be promoted.

These results are in line with the hypotheses of the study and with the cited literature, and can be the starting point of a reflection on gender differences and their effects. In particular, considering goal number 5 of the Sustainable Development Goals [49], these results lay the foundations for an in-depth study of gender equity in the workplace. In many countries around the world, domestic and care work excludes women from the workforce [49]. In order to ensure equal opportunities and the full participation of women at all levels of work, it is perhaps neither useful nor sustainable to cancel these duties. Instead, it is necessary to recognize and value family duties through the promotion of shared responsibility within the family — as appropriate and based on national culture-and the provision of adequate social protection policies, infrastructure, public services, and organizational policies aimed at protecting the work-life balance of all employees.

Finally, another issue that needs to be considered is that these results were obtained from a sample of Italian workers. Italy is one of the countries in Europe with a conservative social structure [50], where the traditional social roles (according to which men are breadwinners and women are housekeepers) persist more than in other countries. Furthermore, both the proportion of female managers and the implementation of work-life balance practices in Italy are below average [50]. In this type of country, more than in others, it is necessary to act on the social, political, and organizational fabric in order to give more support to women for their career development.

\section{Limitations and Future Research}

The study has several limitations that stem mainly from its cross-sectional design and from the use of self-report measures. Although the cited literature has shown the fundamental importance of the perception of subjects regarding the variables examined, it would be useful to add more objective measures in the future, such as feedback from superiors or supervisors. Furthermore, since career opportunities are one of the main variables under study, it would be useful to switch to a longitudinal design in order to verify real career advancements (both positive and negative) some time after the first survey. Finally, the convenience sample limits the generalization of the results, therefore it is advisable to use a sample that is more homogeneous, particularly in terms of type of work, age, and marital status.

\section{Conclusions}

The reference literature has widely demonstrated the relationship between work-life balance and several variables linked to individual and job satisfaction [3,5-9], or, on the contrary, between the unbalance and several variables linked to individual and workrelated stress $[3,7,10,11]$. Some research has also investigated the relationships between 
work-life balance and careers [35,39], although these are quantitatively biased in favor of the female perspective.

This study, despite its limitations, has the merit of simultaneously testing the same hypotheses among women and men. This made it possible to affirm that gender differences in the workplace persist. They concern the career opportunities that workers perceive to have, and which are lower for women. They concern the balance between private life and working life that workers perceive they have, and which is once again lower for women. They concern the connection between the perception of career opportunities and work-life balance, which generates lower well-being for women than for men. However, the results also show that a good perception of work-life balance has the potential to guarantee excellent results in terms of well-being for both women and men. Although this research cannot draw causal relationships, it can certainly offer several insights for practitioners. For example, career opportunities alone are not sufficient to create satisfied employees because career advancements at the expense of the balance between work and family life may not be a sustainable prospect. Furthermore, given the strong interest in the issue of gender equity, evaluating the link between the perception of career opportunities, work-life balance, and well-being is the first essential step in designing interventions that support women in the workplace. Interventions that acknowledge, accept, and enhance gender differences are needed, as well as actions by organizations and practitioners that do not translate, for example, into privileging male candidates to avoid problems, given that work-life balance generates well-being when combined with career development opportunities in both males and females. Although the impact of work-life balance on the lives of men and women could be different, what is certain is that it is a job resource that goes beyond gender [2,20], since the progressive abandonment of the idea of the "traditional family", the steady increase in dual-career couples, and the increase in the number of single parents-regardless of their gender-mean that workers have to juggle more and more responsibilities outside of work [51]. As all the changes that generate well-being in people's daily lives could in turn generate positive changes in their workplace, in the same way, work-life balance practices and policies could generate positive effects on organizations in general. From a broad perspective, work-life balance practices promote employees' motivation and good performance, make the companies more attractive, and help to achieve better corporate social responsibility [51]. From a female perspective, they increase women's full participation, make good use of their skills, and encourage more women to retain and advance in their career. For example, flexible hours, childcare services, telecommuting, compressed workweek arrangements, and job sharing are all practices that research has shown to have positive benefits in terms of employee satisfaction and improved organization productivity $[40,51]$. These practices are associated with the reduction of turnover and absenteeism, the retention of valuable employees, the enhancement of organizational image, and the increase of employee loyalty and commitment, thus proving to be a sustainable Human Resource Management decision.

Finally, valuing gender differences at work and acknowledging the existence of different needs is an important starting point. If every company worked towards this goal, the cultural models of entire organizations, their management strategies, and even the whole of society could be positively influenced. Recognizing diversity helps to capitalize on differences, as better understanding creates better management, which in turn has the potential to increase productivity, motivate, engage, and improve physical and mental health conditions, obtaining positive effects at both individual and organizational levels.

Author Contributions: Conceptualization, F.P.; methodology, G.S.; data curation, F.P.; writingoriginal draft preparation, G.S.; project administration, F.P. All authors have read and agreed to the published version of the manuscript.

Funding: This research received no external funding.

Institutional Review Board Statement: Not applicable. 
Informed Consent Statement: Informed consent was obtained from all subjects involved in the study.

Data Availability Statement: The data presented in this study are available on request from the corresponding author.

Conflicts of Interest: The authors declare no conflict of interest.

\section{References}

1. Kossek, E.E.; Pichler, S.; Bodner, T.; Hammer, L.B. Workplace social support and work-family conflict: A meta-analysis clarifying the influence of general and work-family-specific supervisor and organizational support. Pers. Psychol. 2011, 64, 289-313. [CrossRef] [PubMed]

2. Greenhaus, J.H.; Collins, K.M.; Shaw, J.D. The relation between work-family balance and quality of life. J. Vocat. Behav. 2003, 63, 510-531. [CrossRef]

3. Brough, P.; Timms, C.; O’Driscoll, M.P.; Kalliath, T.; Siu, O.L.; Sit, C.; Lo, D. Work-life balance: A longitudinal evaluation of a new measure across Australia and New Zealand workers. Int. J. Hum. Resour. Manag. 2014, 25, 2724-2744. [CrossRef]

4. Munn, S.L. Unveiling the work-life system: The influence of work-life balance on meaningful work. Adv. Dev. Hum. Resour. 2013, 15, 401-417. [CrossRef]

5. Kossek, E.E.; Ozeki, C. Bridging the work-family policy and productivity gap: A literature review. Community Work Fam. 1999, 2, 139-149. [CrossRef]

6. Allen, T.D.; Herst, D.E.; Bruck, C.S.; Sutton, M. Consequences associated with work-to- family conflict: A review and agenda for future research. J. Occup. Health Psychol. 2000, 5, 278-308. [CrossRef]

7. Haar, J.M.; Russo, M.; Sune, A.; Ollier-Malaterre, A. Outcomes of work-life balance on job satisfaction, life satisfaction and mental health: A study across seven cultures. J. Vocat. Behav. 2014, 85, 361-373. [CrossRef]

8. Frone, M.R. Work-family conflict and employee psychiatric disorders: The national comorbidity survey. J. Appl. Psychol. 2000, 85, 888-895. [CrossRef] [PubMed]

9. Eby, L.T.; Casper, W.J.; Lockwood, A.; Bordeaux, C.; Brinley, A. Work and family research in IO/OB: Content analysis and review of the literature (1980-2002). J. Vocat. Behav. 2005, 66, 124-197. [CrossRef]

10. Behson, S.J. Coping with family-to-work conflict: The role of informal work accommodations to family. J. Occup. Health Psychol. 2002, 7, 324-341. [CrossRef] [PubMed]

11. Fisher-McAuley, G.; Stanton, J.M.; Jolton, J.A.; Gavin, J.A. Modeling the relationship between work/life balance and organizational outcomes. In Proceedings of the Annual Meeting of the Society for Industrial and Organizational Psychology, Orlando, FL, USA, 11-13 April 2003.

12. Glick, P.; Fiske, S.T. The ambivalent sexism inventory: Differentiating hostile and benevolent sexism. J. Pers. Soc. Psychol. 1996, 70, 491-512. [CrossRef]

13. Cinamon, R.G.; Rich, Y. Gender differences in the importance of work and family roles: Implications for work-family conflict. Sex Roles 2002, 47, 531-541. [CrossRef]

14. Plantenga, J.; Hansen, J. Assessing equal opportunities in the European Union. Int. Labour Rev. 1999, 138, 351-379. [CrossRef]

15. Friedman, S.D.; Greenhaus, J.H. Work and Family-Allies or Enemies? What Happens When Business Professionals Confront Life Choices; Oxford University Press: New York, NY, USA, 2000.

16. Sujata, T.L.; Singh, S. Work-life balance issues of women at call centers: A study. J. Manag. Res. 2011, 10, 68-79.

17. Delina, G.; Raya, R.P. A study on work-life balance in working women. Int. J. Commer. Bus. Manag. $2013,2,274-282$.

18. Wattis, L.; Standing, K.; Yerkes, M.A. Mothers and work-life balance: Exploring the contradictions and complexities involved in work-family negotiation. Community Work Fam. 2013, 16, 1-19. [CrossRef]

19. Lewis, S.; Gambles, R.; Rapoport, R. The constraints of a work-life balance approach: An international perspective. Int. J. Hum. Resour. Manag. 2007, 18, 360-374. [CrossRef]

20. Evans, A.M.; Carney, J.S.; Wilkinson, M. Work-life balance for men: Counseling implications. J. Couns. Dev. 2013, 91, 436-441. [CrossRef]

21. Sav, A.; Harris, N. Work-life conflict in Australian Muslims: Is gender important? Gend. Manag. 2013, 28, 486-504. [CrossRef]

22. Haar, J.M. Testing a new measure of work-life balance: A study of parent and non-parent employees from New Zealand. Int. J. Hum. Resour. Manag. 2013, 24, 3305-3324. [CrossRef]

23. Bari, D.; Robert, P. Who benefits more from a balanced life? Gender differences in work-life balance and satisfaction with life in eight post-communist countries. Intersect. East Eur. J. Soc. Politics 2016, 2, 21-41. [CrossRef]

24. Keene, J.R.; Quadagno, J. Predictors of perceived work-family balance: Gender difference or gender similarity? Sociol. Perspect. 2004, 47, 1-23. [CrossRef]

25. Milkie, M.A.; Peltola, P. Playing all the roles: Gender and the work-family balancing act. J. Marriage Fam. 1999, 61, 476-490. [CrossRef]

26. Morgenroth, T.; Ryan, M.K.; Rink, F.; Begeny, C. The (in)compatibility of identities: Understanding gender differences in work-life conflict through the fit with leaders. Br. J. Soc. Psychol. 2021, 60, 448-469. [CrossRef] [PubMed]

27. Nielson, T.R.; Carlson, D.S.; Lankau, M.J. The supportive mentor as a means of reducing work-family conflict. J. Vocat. Behav. 2001, 59, 364-381. [CrossRef]

28. Crompton, R.; Lyonette, C. Work-life balance in Europe. Acta Sociol. 2006, 49, 379-393. [CrossRef]

29. Yavas, U.; Babakus, E.; Karatepe, O.M. Attitudinal and behavioral consequences of work- family conflict and family-work conflict: Does gender matter? Int. J. Serv. Ind. Manag. 2008, 19, 7-31. [CrossRef] 
30. Rehman, S.; Roomi, M.A. Gender and work-life balance: A phenomenological study of women entrepreneurs in Pakistan. J. Small Bus. Enterp. Dev. 2012, 19, 209-228. [CrossRef]

31. Hogg, M.A.; Vaughan, G.M. Social Psychology; Pearson: Harlow, UK, 2013.

32. Wynen, J.; op de Beeck, S.; Ruebens, S. The nexus between gender and perceived career opportunities: Evidence from the U.S. Federal Government. Public Pers. Manag. 2015, 44, 375-400. [CrossRef]

33. Matteazzi, E.; Pailhé, A.; Solaz, A. Part-time employment, the gender wage gap and the role of wage-setting institutions: Evidence from 11 European countries. Eur. J. Ind. Relat. 2018, 24, 221-241. [CrossRef]

34. Karkoulian, S.; Halawi, L. Women and work/life conflict at higher educational Lebanese institutions. Int. J. Bus. Res. 2007, 7, 116-126.

35. Ip, E.J.; Lindfelt, T.A.; Tran, A.L.; Do, A.P.; Barnett, M.J. Differences in career satisfaction, work-life balance, and stress by gender in a national survey of pharmacy faculty. J. Pharm. Pract. 2020, 33, 415-419. [CrossRef]

36. Powell, G.N.; Butterfield, D.A. Investigating the "glass ceiling" phenomenon: An empirical study of actual promotions to top management. Acad. Manag. J. 1994, 37, 68-86.

37. Hochschild, A.R. The Second Shift: Working Parents and the Revolution at Home; Viking: New York, NY, USA, 1989.

38. Adisa, T.A.; Gbadamosi, G.; Osabutey, E.L.C. Work-family balance: A case analysis of coping strategies adopted by Nigerian and British working mothers. Gend. Manag. 2016, 31, 414-433. [CrossRef]

39. Lyness, K.S.; Judiesch, M.K. Gender egalitarianism and work-life balance for managers: Multisource perspectives in 36 countries. Appl. Psychol. 2014, 63, 96-129. [CrossRef]

40. Ezra, M.; Deckman, M. Balancing work and family responsibilities: Flextime and child care in the federal government. Public Adm. Rev. 1996, 56, 174-179. [CrossRef]

41. Galinsky, E.; Stein, P.J. The impact of human resource policies on employees. J. Fam. Issues 1990, 11, 368-383. [CrossRef]

42. Johnson, A.A. The business case for work-family programs. J. Account. 1995, 180, 53-58.

43. Adam, C.; Capilliure, E.; Miquel, M. Work-life balance and firms: A matter of women? J. Bus. Res. 2015, 69, 1379-1383. [CrossRef]

44. Van Veldhoven, M.; Meijman, T.F. Measuring Psycho-Social Workpressure and Workstress with a Questionnaire: The Questionnaire on the Experience and Evaluation of Work (QEEW); Nederlands Instituut voor Arbeidsomstandigheden: Amsterdam, The Netherlands, 1994.

45. Pace, F.; Foddai, E.; Lo Cascio, V.; Passalacqua, C.; Zanca, M.; Civilleri, A. Using the Questionnaire on Experience and Assessment of Work with the Italian population. In Proceedings of the 9th Conference of the European Academy of Occupational Health Psychology, Rome, Italy, 29-31 March 2010; Nottingham University Press: Notthingham, UK, 2010; pp. 407-408.

46. Goldberg, D.P. Manual of the General Health Questionnaire; NFER Publishing: Slough, UK, 1978.

47. Martin, A.; Sanderson, K.; Cocker, F. Meta-analysis of the effects of health promotion intervention in the workplace on depression and anxiety symptoms. Scand. J. Work Environ. Health 2009, 35, 7-18. [CrossRef]

48. Hu, L.; Bentler, P.M. Cutoff criteria for fit indexes in covariance structure analysis: Conventional criteria versus new alternatives. Struct. Equ. Modeling J. 1999, 6, 1-55. [CrossRef]

49. The 17 Goals-Sustainable Development. Available online: https://sdgs.un.org/goals (accessed on 1 December 2021).

50. Straub, C. A comparative analysis of the use of work-life balance practices in Europe. Women Manag. Review. 2007, 22, 289-304. [CrossRef]

51. Lazar, I.; Osoian, C.; Ratiu, P. The role of work-life balance practices in order to improve organizational performance. Eur. Res. Stud. 2010, 13, 201-214. [CrossRef] 